$\mathrm{CO}_{2}$ from fossil-fuel burning, cement production and gas flaring now amount to 22,000 million tons a year ${ }^{9}$. Contributions from our management of the biosphere are less well quantified, but are potentially of the same magnitude. Thus human activities replenish the $\mathrm{CO}_{2}$ deficit more than 45 times over and are equivalent to about 900 additional Mount Etnas.

Berner and Lasaga have characterized the calculation of $\mathrm{CO}_{2}$ degassing from igneous and metamorphic activity as the most vexing problem encountered in modelling the carbon geochemical cycle ${ }^{10}$. In the hope of getting at least a reasonable approximation of $\mathrm{CO}_{2}$ degassing over geological time, modellers have tied all degassing to seafloor THROMBIN RECEPTOR

\section{Variations on a theme}

\section{Robert J. Lefkowitz}

HaRdLY a week seems to pass without news of the cloning and sequencing of the complementary DNA for one or another G protein-coupled receptor with seven transmembrane domains - although each sequence is, of course, of interest, the structural and topographical features of these molecules have begun to seem, well, monotonous. But a report in Cell by Vu et al. ${ }^{1}$, on the expression cloning of a thrombin receptor present on platelets and endothelial cells, now reveals a fresh variation on the structural theme and a unique mechanism of receptor activation. The deduced sequence has a putative cleavage site for the serine protease thrombin in the $\mathrm{N}$-terminal extracellular domain of the receptor. The new terminus created by cleavage at this site apparently constitutes the physiological 'tethered' ligand for the receptor. The discovery will help to explain the molecular basis for one of the important haemostatic actions of throm-

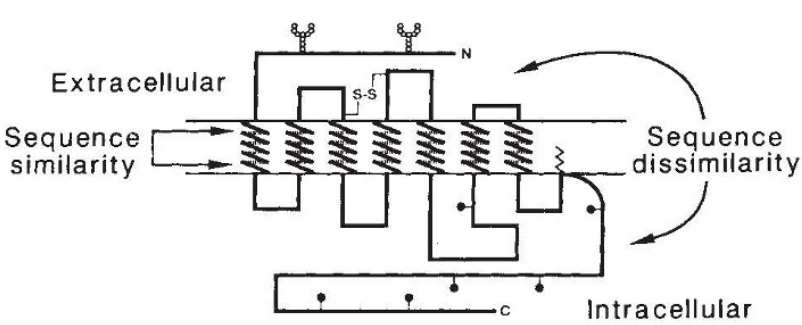

Glycosylation 8 Phosphorylation

Disulphide bond s-ś Fatty acylation ₹ formation

The polypeptide backbone of a prototypic $\mathrm{G}$ protein-coupled receptor crosses the plasma membrane seven times, with each membrane span assuming an $\alpha$-helical conformation. Sites of post-translational modifications (glycosylation, phosphorylation, disulphide bond formation and fatty acyiationt are sitown, anu amino-aciù sequence consenvation in the membrane-spanning domains and divergence in the hydrophilic connecting loops is indicated. Examples of ligands known to interact with the cloned receptors are listed in the box overleaf. bin, activation of platelet aggregation.

Of the various cellular pathways for transwidely studied than that which involves specell-membrane receptors coupled by heterotrimeric, guanine regulatory proteins to effector enzymes and ion channels ${ }^{2,3}$. The of receptors which work in this way is remarkable. Moreover, virtually all of em share a highly conserved structure and topography ${ }^{2}$ (see figure). The first member of this family whose sequence was elucidated Fisual light 'receptor' 4,5 measurements ${ }^{6}$, the presence of predicted, in analogy with bacteriorhodopsin, the distantly related bacterial proton pump for which electron diffraction information is available ${ }^{7}$.

Despite the obvious functional analogies between all $G$ protein-coupled receptors, the publication of the deduced sequence of the mammalian $\beta_{2}$-adrenergic receptor in 1986 , which showed it had considerable sequence similarities and shared topographical features with rhodopsin, was greeted with some surprise ${ }^{8}$. As well as the seven transmembrane domains, these features include an extracellular $\mathrm{N}$ terminus with consensus sequences for $\mathrm{N}$-linked glycosylation; sequence similarity, especially in the presumed membrane-spanning domains; sequence divergence in the connecting hydrophilic loons; a cytoplasmic carboxyl tail and/or large intracellular loop rich in serine and threonine residues, which are sites for regulatory

\section{Strike one}

ALTHOUGH notable for having afflicted public figures such as David Niven and Stephen Hawking, the cause of amyotrophic lateral sclerosis (also known as Lou Gehrig's disease) is still unknown. But about 10 per cent of all cases are familial, and one of the genes thought to be responsible has now been mapped. T. Siddique and colleagues (New Engl. J. Med. 324, 1381-1384; 1991) examined 23 affected families, and demonstrated linkage in a subset of them using markers from the long arm of chromosome 21 . The study points to the existence of at least one other disease locus, and marks an important step forward in characterizing the gene(s) involved and devising possible therapies.

\section{Going up}

SUPERCONDUCTING buckminsterfullerene is following a trend set by the perovskite superconductors four years ago: change an element or two and you get a massive increase in transition temperature. Only last month, A. F. Hebard et al. announced in Nature the totally unexpected finding that sheets of the crystallized $C_{60}$ balls became superconducting below a temperature of $18 \mathrm{~K}$ on doping with potassium. Now, writing in Physical Review Letters (66, $2830-2832 ; 1991$ ), the same group reports that changing the dopant to rubidium raises the onset temperature to $28 \mathrm{~K}$. And even this has been topped by K. Holczer and co-workers (Science 252, 1154-1157; 1991), who find a transition temperature of $30 \mathrm{~K}$, also with rubidium. Only $(\mathrm{Ba}, \mathrm{K}) \mathrm{BiO}_{3}$ and the cuprate materials superconduct at higher temperatures.

\section{Cancer connection}

A POSSIBLE bacterial co-factor for gastric cancer has been identified by J.

Parsonnet and colleagues (Journal of the National Cancer Institute $\mathbf{8 3}$, 640-643; 1991). In patients with intestinal-type cancer attending two hospitals in California, the incidence of infection with Heliobacter pylori was at least 90 per cent, greatly exceeding the levels in the normal population. The study does not demonstrate that infection is causally related to the development of the cancers, but it seems likely that the bacteria may increase the chance of tumours arising (perhaps by stimulating production of cellular mutagens, or by inducing a high rate of cell proliferation following damage to the intestinal cells). Bacterial infections can often be treated sucsessfuly, so eradication sf: H. pylori may turn out to be a way of reducing the incidence of gastric cancer. 